\title{
Isolation and Structure Elucidation, Molecular Docking Studies of Screlotiumol from Soil Borne Fungi Screlotium rolfsii and their Reversal of Multidrug Resistance in Mouse Lymphoma Cells
}

\author{
Bashir Ahmad ${ }^{1}$, Muhammad Rizwan ${ }^{1}$, Abdur Rauf ${ }^{2 *}$, Muslim Raza ${ }^{3}$, Sadiq \\ Azam $^{1}$, Shumaila Bashir ${ }^{4}$, Joseph Molnar ${ }^{5}$, Akos Csonka ${ }^{5}$, Diana Szabo ${ }^{6}$
}

\begin{abstract}
A new compound namely (13-(3,3-dihydroxypropyl)-1,6-dihydroxy-3,4-dihydro-1H-isochromen-8(5H)-one (1) was isolated from an ethyl acetate extract of the borne fungi Screlotium rolfsii. Its chemical structure was elucidated by spectroscopic analysis. Screlotiumol 1 were evaluated for their effects on the reversion of multidrug resistant (MDR) mediated by P-glycoprotein (P-gp) of the soil borne fungi. The multidrug resistant P-glycoprotein is a target for chemotherapeutic drugs in cancer cells. In the present study rhodamine-123 exclusion screening test on human mdr1 gene transfected mouse gene transfected L5178 and L5178Y mouse T-cell lymphoma which showed excellent MDR reversing effect in a dose dependent manner against mouse T-lymphoma cell line. Moreover, molecular docking studies of compound-1 also showed better results as compared with the standard. Therefore the preliminary results obtained from this study suggest that screlotiumol 1 could be used as a potential agent for the treatment of cancer.
\end{abstract}

Keywords: Soil borne fungi - Screlotium rolfsii - screlotiumol 1 - MDR - molecular docking.

Asian Pac J Cancer Prev, 17 (4), 2083-2087

\section{Introduction}

In cancer chemotherapy, multidrug resistance is the main clinical challenge for the active treatment (Szabo and Molnar, 1997). Tumor cells develop resistance to anti-cancer agent through different mechanism. Among these, overexpression of ATP-binding cassette (ABC) proteins is also important. The ABC transporters are transmembrane proteins which bind to ATP and use the energy for the transport of various molecules across cell membranes (Gottesman and Ambudkar, 2001; Leonard et al., 2003). ABC efflux transporters force out a wide range of amphiphilic compounds against the concentration gradient. ABC transporters have performed different physiological functions, normal tissue protection in the liver, kidney and brain. (Gottesman et al., 2002; Sarkadi et al., 2006; Szakacs et al., 2006).

P-glycoprotein (P-gp, ABCB1) was the first identified drug efflux protein coded by the ABCB 1 gene. ABCB1 consists of 1280 amino acids $(170 \mathrm{kDa})$, which organized in two transmembrane domains (Szakacs et al., 2006).ABCB1 protein is overexpressed in several type human cancer, can extrude wide range of drugs (anticancer, antidepressants, antihistamines, antibiotics, antiarrhythmics, HIV protease inhibitors, immunosuppressants, steroids). Different drugs suppress the action of ABCB 1 such as valspodar, tariquidar, dexniguldipine, and tamoxifen (Germann et al., 1993; Lopez and Martinez-Luis, 2014).

Secondly, the multidrug-resistant protein 1 (MRP1, ABCC1) was evaluated in 1992. MRP1 is an efflux pump initially discovered in doxorubicin resistant lung carcinoma cells, which can display a multi-drug resistant phenotype without ABCB1 expression (Cole et al., 1992). MRP1 is overexpressed in the blood-brain barrier, intestines and oral mucosa (He et al., 2011). MRP1 expression is higher in the lung than in any other organ and may have protective roles against air pollution and inhaled toxins (Sakamoto et al., 2013). MRP1 shows poor response to cisplatin therapy with vinorelbine,

${ }^{I}$ Center of Biotechnology and Microbiology, ${ }^{4}$ Department of Pharmacy, University of Peshawar, Peshawar, ${ }^{2}$ Department of Geology, University of Swabi, Ambar, Khyber Pakhtunkhwa, ${ }^{3}$ State Key Laboratory of Chemical Resource Engineering, Beijing University of Chemical Technology, Beijing, China, ${ }^{5}$ Department of Medical Microbiology and Immunobiology, ${ }^{6}$ Department of Oto-RhinoLaryngology and Head-Neck Surgery, Faculty of Medicine, University of Szeged, Szeged, Hungary *For correspondence: mashaljcs@ yahoo.com 
gemcitabine and paclitaxel (Li et al., 2008).

Thirdly, the breast cancer resistance protein (BCRP) is a homodimer, $72 \mathrm{kDa}$ half-transporter member of the ABCG subfamily (ABCG2). Overexpression of BCRP is associated with resistance to a broad range of different anticancer agents including mitoxantrone, anthracyclines, camptothecins, antifolates and flavopiridol (Assaraf, 2006; Bihorel et al., 2007; Robey et al., 2007).

P-gp belongs to the $\mathrm{ABC}$ superfamily of transporters and also plays a role in the MDR of bacteria and yeast against antimicrobials agents. P-gp is considered the best known of the $\mathrm{ABC}$ proteins, due to its involvement in the treatment of cancer and other fatal human diseases(Jones and George, 2004). It consists of 1280 amino acids, arranged in a single chain with two homologous halves having $43 \%$ amino acid similarity. Each half has six transmembrane domains (TM) and a hydrophilic domain containing an ATP-binding site, known as nucleotide binding domain (NBD) (Jara et al., 2013).

The fungi kingdom is one of the most important kingdoms of microorganism in the biosphere (Turner, 2000). Microbial activity is the general term used to indicate the vast range of activities carried out by soil microorganisms. Fungi performing a wide range of function in soil by secreting low molecular weight compound known as secondary metabolites. Secondary metabolites are not essential to the common metabolic pathways of the fungi and are often only produced when these fungi are stressed condition. Nature has evolved to produce a wide range of secondary metabolites. A wide range of pharmaceutically significant compounds belonging to all structural classes were found to be produced by fungi. Until now, approximately 50,000 microbial metabolites have been discovered. S. rolfsii is a soil borne phytopathogenic fungi cause different diseases in plants. Besides their pathogenicity these fungi also produce a wide range of secondary compound. The present study belongs to evaluate the anticancer potentials of of a new secondary metabolites isolated from $S$. rolfsii, their multidrug resistance (MDR), and molecular docking study.

\section{Materials and Methods}

Soil samples collection: Soil samples were collected from different localities of District Malakand, Khyber Pakhtunkhwa Pakistan. The soil samples were collected in sterilized bags and transferred to Laboratory.

Isolation and preservation of fungi: By serial dilution technique, samples were inoculated using different selective fungal media. The fungi were identified by morphologically and microscopically at plant pathology department Agricultural University Peshawar Pakistan. Different fungi were isolated such as Nigrospora, Verticillium and Aspergillus spp. S. rolfsii was selected for the present study.

Extraction of crude metabolites: By using already optimized growth condition, the fresh fungal strains were cultured for production of secondary metabolites. Czapek Yeast-extract Broth (CYB), were prepared and sterilized at $121^{\circ} \mathrm{C}$ for $20 \mathrm{~min} .5$ days old cultured were inoculated in each Erlenmeyer flask containing media. The flask was incubated, at $25^{\circ} \mathrm{C}$ at $150 \mathrm{rpm}$ in shaking incubator. After incubation period, $40 \% \mathrm{HCl}$ were added to each flask, which helps in separating components of media. After vigorously mixing, equal volume of EtOAc was added in each flask. Mycelial biomass was filtered using Cheese cloth. The process was repeated three times. Ethyl acetate portion were separated using separating funnel. Anhydrous sulphate $\mathrm{Na}_{2} \mathrm{SO}_{4}$ were added for dehydration of organics layer and then filtered. The EtOAc were filter using whatman filter paper. The extract were then concentrated at $45^{\circ} \mathrm{C}$ in rotary evaporator.

\section{Fractionation}

The crude EtOAc extract of $S$. rolfsii were suspended in Distilled water and partitioned with n-hexane. So the n-hexane soluble parts were recovered. Similarly, EtOAc soluble fractions were also separated.

\section{Isolation and purification of new compound}

EtOAc fraction of $25 \mathrm{gm}$ was subjected to column chromatography using silica gel. First, slurry were made by mixing $25 \mathrm{gm}$ extract with small quantity of silica gel. Then silica were soaked in $n$-hexane and introduced in the column through funnel. After this the sample were loaded into the column over silica gel, the column was elated with n-hexane, ethyl acetate Isocratic systems or stepwise gradient eluents were employed, depending on the nature of the components and of their separation. The present compound was obtained at 9.0:1.0 of EtOAc: $n$-hexane in yellow like appearance. the purity of compound was confirmed by Thin layer chromatography and subjected to Nuclear Magnetic Resonance for its characterization.

\section{Assay for reversal of MDR in mouse lymphoma cells}

Two cell lines i.e. L5178 MDR and L5178Y were grown on special media known as McCoy`s $5 \mathrm{~A}$ medium containing 10\% heat-inactivated horse serum, also added L-glutamine and antibiotics. Adjustment of cells at a density of $2 \times 10^{6} \mathrm{~mL}$ re-suspended in serum-free McCoy`s $5 \mathrm{~A}$ medium were carried out and distributed in $0.5 \mathrm{~mL}$ aliquots into Eppendorf centrifuge tubes. The tested compound was added at $2 \mu \mathrm{g} / \mathrm{ml}$ final concentrations, and the samples were incubated for 10 minutes at room temperature. For positive control, Verapamil was used (Cornwell et al., 1987; Rauf et al., 2015; Rauf et al., 2016) in $10 \mu \mathrm{g} / \mathrm{ml}$ concentration.

The L5178 MDR and L5178Y parent cell lines were grown in McCoy`s 5A medium containing 10\% heatinactivated horse serum, was completed with L-glutamine and antibiotics. The cells were adjusted to a density of $2 \times 10^{6} \mathrm{~mL}$ re-suspended in serum-free McCoy`s $5 \mathrm{~A}$ medium and distributed in $0.5 \mathrm{~mL}$ aliquots into Eppendorf centrifuge tubes. The tested compound was added at $2 \mu \mathrm{g} /$ $\mathrm{ml}$ final concentrations, and the samples were incubated for 10 minutes at room temperature. Verapamil was applied as positive control (Cornwell et al., 1987) in 10 $\mu \mathrm{g} / \mathrm{ml}$ concentration. In the next step, Indicator rhodamine $12310 \mu \mathrm{L}(5.2 \mu \mathrm{M}$ final concentration) was added to the samples and incubated for $20 \mathrm{~min}$ at $37^{\circ} \mathrm{C}$, twice washed and re-suspended in $0.5 \mathrm{~mL}$ PBS. Partec CyFlow flow cytometer (Münster, Germany) was used to measure of 
Isolation, Structure Elucidation, and Molecular Docking of Screlotiumol 1 and Reversal of MDR in Mouse Lymphoma Cells

fluorescence of the cell population. The tested compound was dissolved in DMSO, which was also used as solvent control. The percentage of mean fluorescence intensity was calculated for the treated MDR and parental cell lines as compared with the untreated cells. The activity ratio $\mathrm{R}$ was calculated via the following formula (Cornwell et al., 1987) on the basis of the measured fluorescence values

$$
\mathrm{FAR}=\frac{\mathrm{MDR}_{\text {treated }} / \mathrm{MDR}_{\text {control }}}{\text { parental }_{\text {treated }} / \text { parental }_{\text {control }}}
$$

Isolation of screlotiumol (1)

EtOAc fraction (25 gm) was subjected to normal phase column chromatography. The column was eluted with n-hexane: EtOAc (1:9) which afforded a yellow compound named screlotiumol. The structure was elucidated by advanced NMR analysis.

Screlotiumol 1 was isolated as a yellow solid from ethyl acetate fraction of Screlotium rolfsii.

Screlotiumol was identified as $\mathrm{C}_{12} \mathrm{H}_{16} \mathrm{O}_{5}$ (M.p=133$\left.136^{\circ} \mathrm{C}\right)$ EI-MS spectrum. IR (KBr, Cm-1) showed absorption peaks at 3355-3650 for $\mathrm{OH}$ stretching, 2988 $\mathrm{CH}$ saturated stretching, $1650 \mathrm{C}=\mathrm{O}$ stretching. 1H-NMR (400 MHz, MeOD) $\delta \mathrm{H}: 6.79$ (H-2, s), 2.65, $1.99(2 \mathrm{H}-4, \mathrm{~m})$, 2.30, $1.99(\mathrm{H}-5, \mathrm{~m}: 2 \mathrm{H}), 3.6,(\mathrm{H}-6, \mathrm{~m}), 4.84(\mathrm{H}-8, \mathrm{~s}), 1.41$, $1.39(\mathrm{H}-11, \mathrm{~m}, 2 \mathrm{H}), 1.67,1.66(\mathrm{H}-12, \mathrm{~m}, 2 \mathrm{H}), 4.20(\mathrm{H}-13$, $\mathrm{d}, \mathrm{j}=2.3)$ respectively. $13 \mathrm{C} \mathrm{NMR} ;\left(\mathrm{CDCl}_{3}, 150 \mathrm{MHz}\right) \delta \mathrm{c}$ : 187.2 (C-1), 108.2 (C-2), 199.9 (C-3), 38.5 (C-4), 38.6 (C-5), 66.9 (C-6), 88.5 (C-8), 136.6 (C-9), 162.2 (C-10), 25.9 (C-11), 33.0 (C-12) and 100.9 (C-13) respectively. On the basis of the advanced spectral analysis, the chemical structure of a new compound 1 was identified as (13-(3,3-dihydroxypropyl)-1,6-dihydroxy-3,4-dihydro$1 \mathrm{H}$-isochromen-8(5H)-one (1). Furthermore the structure of compound 1 was confirmed by HBMC correlations.

\section{Docking studies}

$\mathrm{X}$-ray crystallographic structure of P-glycoprotein (Pgp) having PDB four letter code 4Q9L of resolution $3.80 \AA$ was retrieved from the protein data bank (PDB) (Berman et al., 2000). This crystallographic structure was subjected to the energy refinement by swiss PDB viewer v4.1.0 program (Guex and Peitsch, 1997). The compound-1 and the Rhodamine 123 structures were drawn through Chem sketch (Li et al., 2004) and Avogadro,s software (Hanwell et al., 2012).

The docking of Compound-1 and standard Rhodamine123 were carried out through Autodock Vina (Trott and Olson, 2010) and i-GEMDOCKv 2.1 software's (Hsu et al., 2011). The docking method was optimized by an already co-crystallized ligand of the P-gp receptor.

Furthermore, all the default parameters were used for both Autodock Vina and i-GEMDOCKv 2.1 software's (Rauf et al., 2015a; Rauf et al., 2015b; Rauf et al., 2015c). The docking analysis was carried out through LIGPLOT+ version v.1.4.5 (Wallace et al., 1995), PyMOL (DeLano, 2002) and Discovery studio visualizer softwares (Visualizer, 2005).

\section{Results and Discussion}

To evaluate the ABCB 1 transporter modulating<smiles></smiles>

Chemical structure of screlotiumol (1)

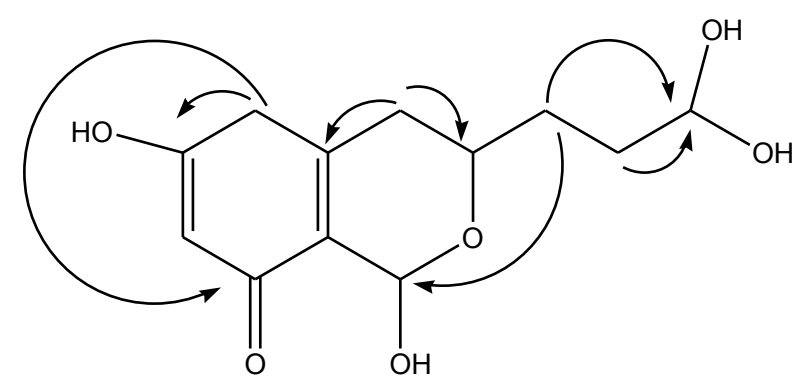

Figure 1. Key HBMC correlation of screlotiumol (1)

Table 1. Effects of Compound-1 on the Rhodamine123 Accumulation Assay in L5178 MDR Mouse Lymphoma Cell

\begin{tabular}{|c|c|c|c|c|c|c|c|}
\hline & Sample & $\begin{array}{c}\text { (final concentration) } \\
\mu \mathrm{g} / \mathrm{ml}\end{array}$ & FSC & $\mathrm{SSC}$ & Mean & FAR & Peak Ch \\
\hline 1 & PAR & - & 2315 & 684 & 70.8 & - & 69.8 \\
\hline 2 & PAR & - & 2134 & 603 & 65.5 & - & 67.3 \\
\hline \multirow[t]{2}{*}{3} & MDR & - & 2339 & 753 & 2.01 & - & 1.6 \\
\hline & MDR MEAN & - & 2326 & 914 & 1.64 & - & 1.54 \\
\hline 4 & Verapamil & 10 & 2329 & 711 & 21.9 & 13.35 & 27.4 \\
\hline 8 & 1 & 2 & 1843 & 1137 & 10.34 & 14.07 & 16.41 \\
\hline 18 & DMSO & $0.20 \%$ & 2247 & 759 & 1.02 & 0.62 & 0.931 \\
\hline 19 & MDR & - & 2313 & 1076 & 1.27 & - & 1.49 \\
\hline
\end{tabular}

Table 2. Docking Statistics of Compound-1 and the Standard Rhodamine123 Against Mice P-glycoprotein

\begin{tabular}{lcccc}
\hline \multicolumn{1}{c}{ Compound-Name } & $\begin{array}{c}\text { Autodock Vina } \\
\text { B. Affinity }\end{array}$ & Total Energy & i-GEM DOCK \\
& -6.8 & -76 & -56 & -20 \\
Compound-1 & -8.2 & -87 & -86 & 0 \\
Rhodamine123 & ED & -1 & 0 \\
\hline
\end{tabular}




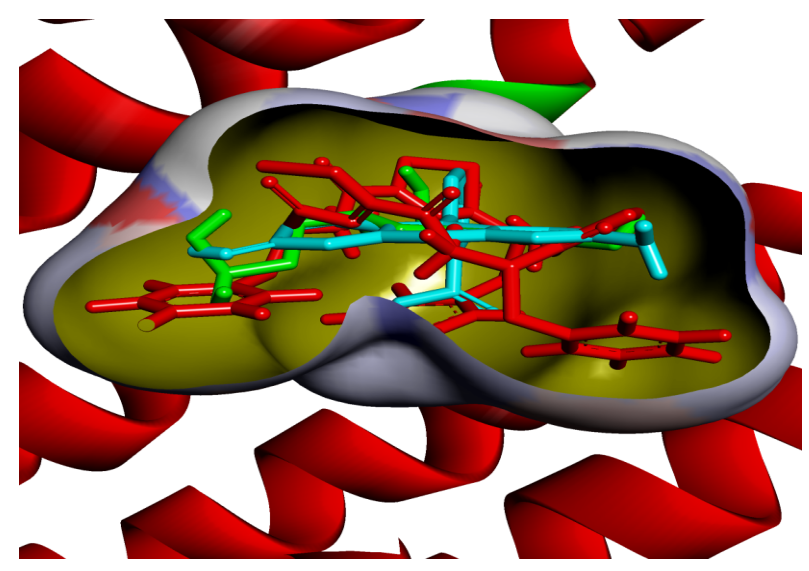

Figure 2. The Predicted Docked Poses of Compound-1 in the Binding Region of P-gp. In the above figure 2 red color sticks represent co-crystallized ligand with superimposed green color stick compound-1 and the cyan color stick represent Rhodamine123

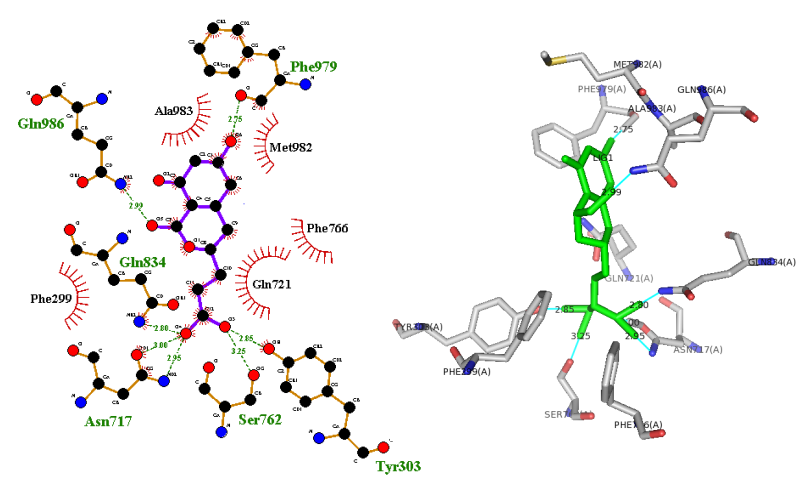

Figure 3. The 2-D and the 3-D Binding Interactions of Compound-1 with the p-gp

potential, the fluorescence activity ratio (FAR) value was used. In the flow cytometry, the value of SSC (side scatter count) and FSC (forward scatter count) were increased, which indicates that the compounds (1) had membrane effect and the granulation of cytoplasm was increased. The FAR values obtained by using compound 1 , indicating that compound 1 is very effective MDR modulator in a short time experiment. Verapamil, which is a calcium channel blocker and chemosensitizer, was used as a positive control. On MDR mouse lymphoma cells the compound 1 was screen in one $2 \mu \mathrm{g} / \mathrm{ml}$ concentration. The 1 was strong modulators of the efflux pump activity (FAR 10.22, $2 \mu \mathrm{g} / \mathrm{ml}$ )

Computational docking analysis has vital role in the discovery of new drugs. It primarily predicted the inhibiting potency of new compounds against the drug target proteins. Our molecular docking studies revealed that the docking of compound- 1 which can co-relate with the in-vitro results. The docking experiment of standard Rhodamine 123 and compound-1 was carried out against the crystal structure of P-gp. The docking of compound-1 (Table 2) revealed a similar result as indicated from the Figure 2. The interaction analysis of compound-1 (Figure 3) shows two types of contacts. One is hydrogen bonding and another is hydrophobic contacts, if such type of interactions are present in the new compounds then it will shows a good mediating biological activities. There are a total of seven hydrogen bonding with binding site of compound-1, including them two hydrogen bond observed from the Asn 717 with a distance of $3.00 \AA$ and $2.95 \AA$. The other five hydrogen observed from the residues

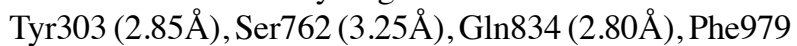
$(2.75 \AA)$ and $\operatorname{Gln} 986(2.99 \AA)$. The hydrophobic contacts of compound-1 in the binding site of P-gp were also observed from the surrounding residues such as Phe299, Gln721, Phe766, Met982 and Ala983.

Moreover, further detail study will be needed to explore the anticancer potential of compound-1 against the targeted receptor. The preliminary result obtained from this study will leads to the discovery of new therapeutic agent for the treatment of cancer.

\section{References}

Assaraf YG (2006). The role of multidrug resistance efflux transporters in antifolate resistance and folate homeostasis. Drug Resistance Updates, 9, 227-46.

Berman HM, Westbrook J, Feng Z, et al (2000). The protein data bank. Nucleic acids Res, 28, 235-42.

Bihorel S, Camenisch G, Lemaire M, et al (2007). Modulation of the brain distribution of imatinib and its metabolites in mice by valspodar, zosuquidar and elacridar. Pharmaceutical Res, 24, 1720-8.

Cole S, Bhardwaj G, Gerlach J, et al (1992). Overexpression of a transporter gene in a multidrug-resistant human lung cancer cell line. Science-new York Then Washington, 258, 1650.

Cornwell MM, Pastan I, Gottesman MM (1987). Certain calcium channel blockers bind specifically to multidrug-resistant human KB carcinoma membrane vesicles and inhibit drug binding to P-glycoprotein. J Biological Chemistry, 262, 2166-70.

DeLano WL (2002). PyMOL. delano scientific, san carlos, CA, 700.

Germann UA, Pastan I, Gottesman MM (1993). P-glycoproteins: mediators of multidrug resistance. Seminars Cell Biol, Elsevier, 4, 63-76.

Gottesman MM, Ambudkar SV (2001). Overview: ABC transporters and human disease. J Bioenergetics Biomembranes, 33, 453-8.

Gottesman MM, Fojo T, Bates SE (2002). Multidrug resistance in cancer: role of ATP-dependent transporters. Nature Reviews Cancer, 2, 48-58.

Guex N, Peitsch MC (1997). SWISS-MODEL and the Swiss-Pdb Viewer: an environment for comparative protein modeling. Electrophoresis, 18, 2714-23.

Hanwell MD, Curtis DE, Lonie DC, et al (2012). Avogadro: An advanced semantic chemical editor, visualization, and analysis platform. J. Cheminformatics, $\mathbf{4}, 17$.

He SM, Li R, R Kanwar J, et al (2011). Structural and functional properties of human multidrug resistance protein 1 (MRP1/ ABCC1). Current Med Chem, 18, 439-81.

Hsu KC, Chen YF, Lin SR, et al (2011). iGEMDOCK: a graphical environment of enhancing GEMDOCK using pharmacological interactions and post-screening analysis. BMC bioinformatics, 12, 33 .

Jara GE, Vera DMA, Pierini AB (2013). Binding of modulators to mouse and human multidrug resistance P-glycoprotein. A computational study. J Molecular Graphics and Modelling, 46, $10-21$.

Jones P, George A (2004). The ABC transporter structure and mechanism: perspectives on recent research. Cellular 

Molecular Life Sciences CMLS, 61, 682-99.

Leonard GD, Fojo T, Bates SE (2003). The role of ABC transporters in clinical practice. Oncologist, 8, 411-24.

Li XQ, Li J, Shi SB, et al (2008). Expression of MRP1, BCRP, LRP and ERCC1 as prognostic factors in non-small cell lung cancer patients receiving postoperative cisplatinbased chemotherapy. International J Biological Markers, 24, 230-7.

Li Z, Wan H, Shi Y, et al (2004). Personal experience with four kinds of chemical structure drawing software: review on ChemDraw, ChemWindow, ISIS/Draw, and Chem Sketch. J Chemical Information Computer Sciences, 44, 1886-90.

Lopez D, Martinez-Luis S (2014). Marine natural products with P-glycoprotein inhibitor properties. Marine Drugs, 12, 525-46.

Rauf A, Uddin G, Siddiqui BS, et al (2015). A rare class of new dimeric naphthoquinones from diospyros lotus have multidrug reversal and antiproliferative effects. Frontiers Pharmacol, 6, 293.

Rauf A, Uddin G, Raza M, et al (2016). Reversal of multidrug resistance in mouse lymphoma cells by extracts and flavonoids from pistacia integerrima. Asian Pac J Cancer Prev, 17, 51-5.

Rauf A, Uddin G, Raza M, et al (2016). Reversal of multidrug resistance and computational studies of pistagremic acid isolated from pistacia integerrima. Asian Pac J Cancer Prev.

Rauf A, Khan R, Raza M, et al (2015a). Suppression of inflammatory response by chrysin, a flavone isolated from Potentilla evestita Th. Wolf. In silico predictive study on its mechanistic effect. Fitoterapia, 103, 129-35.

Rauf A, Saleem M, Uddin G, et al (2015b). Phosphodiesterase-1 Inhibitory Activity of Two Flavonoids Isolated from Pistacia integerrima JL Stewart Galls. Evidence-Based Complementary and Alternative Med, 2015.

Rauf A, Uddin G, Khan H, et al (2015c). Anti-tumour-promoting and thermal-induced protein denaturation inhibitory activities of $\beta$-sitosterol and lupeol isolated from Diospyros lotus L. Natural Product Res, 1-3.

Robey RW, Polgar O, Deeken J, et al (2007). ABCG2: determining its relevance in clinical drug resistance. Cancer Metastasis Reviews, 26, 39-57.

Sakamoto A, Matsumaru T, Yamamura N, et al (2013). Quantitative expression of human drug transporter proteins in lung tissues: analysis of regional, gender, and interindividual differences by liquid chromatographytandem mass spectrometry. J Pharmaceutical Sciences, 102, 3395-406.

Sarkadi B, Homolya L, Szakacs G, et al (2006). Human multidrug resistance $\mathrm{ABCB}$ and $\mathrm{ABCG}$ transporters: participation in a chemoimmunity defense system. Physiological reviews, 86, 1179-236.

Szabo D, Molnar J (1997). The role of stereoselectivity of chemosensitizers in the reversal of multidrug resistance of mouse lymphoma cells. Anticancer Res, 18, 3039-44.

Szakacs G, Paterson JK, Ludwig JA, et al (2006). Targeting multidrug resistance in cancer. Nature reviews Drug Discovery, 5, 219-34.

Turner G (2000). Exploitation of fungal secondary metabolites old and new. Microbiology Today, 27, 118-121.

Trott O, Olson AJ (2010). Auto dock vina: improving the speed and accuracy of docking with a new scoring function, efficient optimization, and multithreading.J Computational Chemistry, 31, 455-61.

Visualizer DS (2005). Accelrys software inc. Discovery Studio Visualizer, 2.

Wallace AC, Laskowski RA, Thornton JM (1995). LIGPLOT: a program to generate schematic diagrams of protein-ligand 